THE STATE OF INFORMATION SYSTEMS IN AUSTRALIAN UNIVERSITIES -

\title{
TASMANIAN REPORT
}

\author{
Dr Gail Ridley \\ IT Control Research Group \\ School of Accounting \& Corporate Governance \\ University of Tasmania. \\ Gail.Ridley@utas.edu.au
}

\begin{abstract}
This paper examines Information Systems at the University of Tasmania. The study draws upon a theoretical framework reported earlier. In common with studies conducted elsewhere in the region, this investigation utilised data collected on five themes. The study aimed to characterise Information Systems at the University of Tasmania, as well as to investigate the relationship between the impact of local contingencies on a discipline and its degree of professionalism, within the Tasmanian context. Data were collected through a qualitative survey with seven influential academics associated with the discipline at the University, and from statistical sources. The findings suggest that an inverse relationship exists between the impact of local factors and the degree of professionalism in this IS setting. A surprising finding was that the relationship found varied for research and teaching issues.
\end{abstract}

\section{INTRODUCTION}

The current paper reports upon a study of the state of the Information Systems (IS) discipline in the only university in Tasmania, and draws upon a theoretical framework outlined in an earlier chapter in this volume. The theoretical construct that guides the study has been presented in the earlier framework paper in this edition and will not be restated. This study forms a sub-study of a wider investigation, comprised of a number of levels. It is one of a series of similar studies undertaken in each Australian state and the Australian Capital Territory, and reported upon elsewhere in this volume.

Tasmania is a unique state in Australia as it has only a single university, which is one of the oldest universities in Australia. The University of Tasmania was established in 1890 in Hobart. In 1991 the University merged with the Tasmanian State Institute of Technology in Launceston, forming the second campus, in the North of the State. Then in 1995 the North-West Centre was opened in Burnie, and renamed the Cradle Coast Campus in 2005. Although the University of Tasmania has just over 12,000 students, it offers one of the widest selection of courses in Australia (University of Tasmania 2005), including 13 within the discipline of Information Systems. 


\begin{abstract}
AIMS OF THE STUDY
This study aims to both characterise the state of the Information Systems academic discipline in the University of Tasmania (UTas), and also contribute to a better understanding of the same discipline in universities throughout Australia. Consequently, the data gathered for the study will be analysed at three levels. Table 1 sets out the three levels.

The first level of analysis will be reported in this current paper and provides a descriptive examination of IS at the University of Tasmania from qualitative and quantitative sources. The second level of analysis will also be reported in this paper, and aims to examine in the Tasmanian IS academic context, the postulation contained within the theoretical framework that an inverse relationship exists between the impact of local contingencies on a discipline and its degree of professionalism.
\end{abstract}

At the third level of analysis, some of the data gathered for the current study will be utilised for a cross-case analysis, and reported elsewhere. The cross-case analysis will draw upon the remainder of the theoretical framework, which contends that a discipline will establish over time with the development of Mechanisms of Control and a Core Body of Knowledge. This component of the theoretical framework cannot be investigated in a single case, as cross-regional analysis is required on such issues as key IS research and teaching topics, and whether a unique symbol set exists for the discipline. Moreover, some Australian longitudinal data will be needed at this third level.

Each state study, although guided by the theoretical framework developed for the Australian project, will be influenced by the background and interests of the IS academics within the state. However, consistent with the content of the other state reports, the following issues have been examined within Tasmania IS academia:

- Extent to which IS is/was impacted by local contingencies

- $\quad$ Extent to which IS is/was identified as a separate field at the University

- The distinctive features of the IS curriculum at the University

- $\quad$ The distinctive features of IS research at the University

- $\quad$ Perception of the Key People in the Region who have impacted IS at UTas

\begin{tabular}{|c|c|l|}
\hline $\begin{array}{c}\text { Covered } \\
\text { in this } \\
\text { Paper }\end{array}$ & Level & Scope \\
\hline & 1 & Descriptive analysis using quantitative \& qualitative sources \\
\hline & 2 & $\begin{array}{l}\text { Examines whether an inverse relationship exists between impact of } \\
\text { local contingencies on discipline \& degree of professionalism }\end{array}$ \\
\hline & 3 & Cross-case analysis drawing upon theoretical framework \\
\hline
\end{tabular}

Table 1 Three Levels of Analysis Discussed in Study 


\section{BACKGROUND}

The reader is referred to an extensive review of the literature on the development of disciplines that has been provided in the earlier Framework paper of this volume. However, a brief overview of the work of IS researchers who have examined the state or development of IS in world regions is presented below.

Little prior research of this kind in an Australian setting has been undertaken before, apart from the work of Ridley (for example, Ridley 1996; Ridley, Goulding, Pervan \& Lowry 1998), who examined the state of the IS discipline in Australia, using two quantitative surveys, to find that the discipline at that time was at an early state of maturity.

Not long after the research by Ridley and co-authors was published, related work was undertaken in Europe by Avgerou, Siemer and Bjorn-Andersen (1999), and in North America by Watson, Taylor, Higgens, Kandec and Meeks (1999). Avgerou et al. (1999) used a survey methodology and found that European IS researchers were concerned that their discipline may be absorbed by another. Watson et al. (1999) conducted telephone interviews with 17 academic IS leaders to uncover some doubt on whether the discipline could maintain or expand its position. The leaders also shared the concern of European IS academics about possible absorption by better established disciplines.

The methodology used for the current study is presented next.

\section{METHODOLOGY}

The case study method was used for this study, derived from the approach of Yin (2003). An interpretive philosophy was utilised, seeking "rich insight” (Walsham 1995). The Tasmanian case study was based on a detailed case study protocol developed by the Queensland study team members, with input from the study team members from elsewhere in Australia. The protocol aimed to bring about comparability across the states, consistency across the individual state case studies and efficiency in data gathering.

Ethics approval for the study for all state teams in Australia was obtained by the Queensland University of Technology, and later ratified by UTas.

The primary method used to gather data was a qualitative survey, using an open-ended questionnaire, which was emailed as an attachment to the majority of the participants in November, 2005, and then returned by email. The instrument was piloted in the School of Information Systems at UTas. All participants were first contacted by phone or approached in person, with the exception of one participant who was located outside Australia, and another who worked elsewhere at the University, and was no longer associated with the Information Systems discipline. Where a response had not arrived within the timeframe indicated for the return of the questionnaire, contact was again made with the academic, either in person or by email, to encourage them to respond. 
Eight academics who were currently closely involved with IS at UTas, or had been in the past, were approached to participate in the survey. Of these, five were currently involved in either IS teaching or research, or both, at the University in the School of IS. Of the remaining three academics, two had been employed in the Information Systems discipline at the University in the past, and were working as an IS academic outside Tasmania, while the third was employed in an allied discipline elsewhere at UTas at the time the data were collected. Of the participants, four had been employed as a head of school or in a more senior position, either at the time they participated in the study, or in the past, while two had had an extended association with the School of IS. All the three participants no longer working with IS academics at UTas were known internationally in IS or an allied discipline. The participants were chosen for their long-standing connection with the School of IS at UTas and/or because their present or past position, or international links, made it likely that they would have a broad understanding of IS. Both male and female academics were contacted and responded, but there was a higher proportion of males in both categories. Although the author of this paper was also a current member of the School of IS at UTas, her views were not included in the data collection and care was taken to try to exclude them from the analysis. This was done by having another person trained in IS research methods categorise the data after it had been stripped of identifying characteristics, and where the classification differed, agreement was reached after discussion.

The survey method was used as some of the participants were located in other states or nations, so that interviewing would have been difficult. An interview was conducted with one of the participants, using the same interview protocol, with the researcher recording written notes. Some of the responses took participants up to two hours to complete, and the participants were encouraged to write as much detail as they needed, where they considered the questions relevant. Consequently, the survey and interview captured broad perceptions of the state of IS at UTas, as well as points of differentiation and distinctive characteristics of IS at that University.

Existing statistical and archival material was also collated to supplement the data obtained from the participants, and to facilitate some degree of triangulation. A summary of the statistical information was emailed to those participants currently employed at the School of Information Systems, with a request to advise where the information required updating. None of the participants indicated that they wanted to modify the summary of the statistical summary. The collated statistical information was not sent to those study participants currently employed outside of the School, as they had less capacity to verify current information about the School.

A thematic analysis process was followed, allowing the integration of both the qualitative data collected from participants and the quantitative data collated from other sources (Dixon-Woods, Agarwal, Jones, Young \& Sutton 2005). Although thematic analysis can be data driven, in this study the themes were driven by those in the theoretical framework referred to earlier. The discussion reported in the findings section below was "weighted towards themes that appear to have a high level of explanatory value", rather than reflecting how frequently the themes were reported (Dixon-Woods et al. 2005, p. 47).

The notes made during the interview with one participant were recorded in electronic format, and then all the responses for each question were collated by copying the text forwarded by email. The text relating to each question was then examined for themes arising from the framework. The themes, and issues arising from the themes, have been presented below, grouped into the five major categories set out in Section 1.1. Statistical and archival data have been incorporated into the discussion relating to the themes, where relevant. The discussion of the themes in Section 4.0 
below presents the findings of the descriptive examination of IS at UTas from qualitative and quantitative sources, and forms the first level of analysis for this study.

Following discussion of the themes, two tables were prepared to analyse the data at the second level. The second level analysis examines whether an inverse relationship exists between the impact of local contingencies on a discipline and its degree of professionalism, in the Tasmanian IS academic context. In order to do this, the impact of local contingencies on IS teaching and research at UTas, and its degree of professionalism, were each independently categorised by two people trained in IS research methods as high, medium or low. If the classification varied, agreement was reached after discussion. This analysis allowed an evaluation to be made of the relationship between the impact of local contingencies on IS at UTas and its degree of professionalism, using the meaning of each term set out in the previous framework paper. However, professionalism was regarded in the theoretical framework as having high task certainty, routinisation of activities and a clear division of labour. Where a discipline was not highly professionalised, the control of work process would be decentralised, with limited routinisation of tasks (Whitley 1984).

After the paper was written, the original participants were invited to comment on it. Five participants took up this invitation.

\section{ANALYSIS AND FINDINGS: LEVEL ONE}

Section 4.0 first presents demographic characteristics of the respondents, as well as a discussion of the administrative placement of the School of IS and the size of the IS presence at UTas. Then the findings and discussion follow, relating to the five common themes listed in the aims of this study.

\section{Respondent characteristics and IS administrative placement and size}

Responses were received from all people contacted, with the exception of one researcher based at the School of Information Systems. Some participants felt unable to respond to some questions, particularly where they no longer worked in the School of Information Systems. Where a participant did respond to a question as relevant, the replies varied in length from two words to several long paragraphs. The longest response to the questionnaire ran to five and one-half pages of single-spaced text. Many of the responses to the same question from different participants varied considerably in the way that it was answered. Consequently, it can be seen that the replies were far from cursory, and enabled personalised, reflective and deep responses, beyond what was likely to be obtained if all the data had been collected via interview. The demographic characteristics of respondents are shown in Table 2:

$\begin{array}{cc}\text { Gender } & \\ \text { Male } & 5 \\ \text { Female } & 2 \\ & \\ & \\ \text { Age (estimated) } & \\ 40-50 & 2 \\ 51-60 & 3 \\ 61-70 & 2\end{array}$

Academics with $\mathrm{PhD}$

Discipline of PhD

Information Systems

Computer Science

Current Position

Professor

Assoc Prof

Snr Lecturer

Lecturer
5

3

2

3

2

1 
Table 2: Respondent Demographics

UTas introduced a major in Information Technology around 1987. However, it was only around 1992 that a recognisable Information Systems program was introduced in the University. Prior to January 1997, the academic discipline of IS was co-located with computing in the Department of Computer Science, in a Faculty of Science and Engineering. The School of Information Systems was formed in January 1997, and administratively located within a Faculty of Commerce (from 2006 the Faculty of Business). The School of Information Systems is one of four schools located within the Faculty, the others being Management, Accounting and Corporate Governance, and Economics and Finance. While the other three schools in the Faculty at the Hobart campus are physically located together on different floors of a building on the steep slopes of Mount Nelson, the School of Information Systems is situated at the other end of the University campus, a 15-minute walk away towards the Derwent River. The School moved into a purpose built building erected in 2002, which overlooks the University Oval in the foreground, and the River in the middle distance. In 2005 the School delivered IS units at six locations: Hobart, Launceston and the Cradle Coast Campus in Tasmania, Shanghai and Fuzhou in China and Jakarta in Indonesia. The first three locations are campuses of UTas. The other three locations are campuses of other universities, where an agreement is in place for delivery of UTas programs.

At the time that the data were collected in late 2005, 17 staff members were employed either fulltime or part-time, and based in the School of Information Systems. Of these, 13 were academic (one part-time), while two undertook research positions. The School had three administrative officers (one part-time), and one technical officer employed under a Service Level Agreement with the University. Of these staff members, all but eleven academic staff members were based in Hobart, two were located in Launceston and no School of IS staff members were permanently based in the Cradle Coast Campus, or in Shanghai, Fuzhou or Jakarta. In addition, an honorary research associate carried out research and paid casual teaching in Hobart, while a recently retired academic undertook considerable casual lecturing for the School from both the Launceston and Hobart campuses. School of IS students based at the Cradle Coast Campus were served either by visiting staff members from Hobart or Launceston, and/or by videoconference or other remote teaching approaches, particularly WebCT Vista. Delivery to Shanghai, Fuzhou and Jakarta was undertaken through occasional block teaching by UTas staff, often supplemented by local teaching staff and electronic delivery through WebCT Vista. Table 3 sets out the staff and teaching locations.

In Semester 2, 2005, the School had 1010 students based in the six locations, which represented around 800 EFTSUs in total. Eight undergraduate programs existed at that time, four graduate coursework programs, and a $\mathrm{PhD}$ program. Further coursework graduate programs will be introduced in 2006. The programs on offer at the School of Information Systems as at the end of 2005 have been set out in Appendix 1.

\begin{tabular}{|l|c|c|c|c|}
\hline $\begin{array}{l}\text { UTas teaching } \\
\text { locations }\end{array}$ & Hobart & Launceston & Cradle Coast & $\begin{array}{l}\text { Shanghai, } \\
\text { Fuzhou, } \\
\text { Jakarta }\end{array}$ \\
\hline Academic staff & 11 & 2 & 0 & 0 \\
\hline General staff & 4 & 0 & 0 & 0 \\
\hline
\end{tabular}

Table 3 Summary of Staffing and Teaching Centres 


\section{IMPACT OF LOCAL CONTINGENCIES}

The following section sets out the extent to which IS was believed by the survey participants to be impacted by local contingencies at UTas. Three broad issues are considered, namely the extent to which the IS curriculum and research had been affected by local factors, the variation in both by campus, and an examination of how IS was affected by local factors when compared against other disciplines at UTas.

\section{Curriculum and teaching issues}

The multi-campus operation of the University within Tasmania, and the associated delivery of IS in those three centres, was seen to have come about, at least in part, by the influence of Tasmanian politicians. A participant referred to the difficulty in adjusting the staff profile to student demand, which varies by campus, and balancing this issue and others due to funding pressures.

Course advisory committees were another way that local perspectives had impacted on the courses in the past. These committees which met irregularly were established for the IS programs when the School of IS commenced in 1997. Although course advisory committees had provided feedback on the curriculum of the Bachelor of Information Systems and Honours programs, they did not influence their design or development significantly. However the Master of Information Systems (MIS) program was both designed and introduced as a response to demand for graduate professional development in IS from the Tasmanian State Government. The MIS Course Advisory Committee played a significant role in both the curriculum and delivery modes for that program between 1997 and 1999. In contrast, the Bachelor of Information Systems degree curriculum was strongly influenced by the broader issues of national published curricula, which included IS'95 (Longnecker, Clark, Couger, Feinstein \& Clark 1995) and IRMA (IRMA 1996).

Another participant commented on a need for greater involvement of course advisory committees in more recent years to update the curriculum, but noted the introduction of logistics to the undergraduate curriculum in the past few years as a response to external demand. Two other respondents saw little evidence of the School's curriculum responding to local external factors. The latter participants were more recent, or relatively recent arrivals in the State, and had not worked in Tasmania at the time that most of the courses had been developed. However, one of these participants noted that the School had responded to international demands in a considerable way, making reference to how the curriculum had changed to accommodate DIMIA requirements and those of the international market.

The nature of the IS programs varied considerably, depending on location. Traditionally the majority of the School's students had been located in Hobart, while Launceston had the second largest proportion of students. Few students were based in Burnie, and it has not been possible to complete an undergraduate IS degree there. However, since the School had started to deliver IS into Shanghai the distribution of students by campus had changed dramatically. For example, as at November, 2005, 75\% of the total EFTSU of 800 (1010 students) of the School of IS were international students. Although some of the international students studied on-shore at Tasmanian campuses, $61 \%$ of the School's total EFTSU was enrolled off-shore in China. A total of 59\% of the School's EFTSU was enrolled in a Bachelor of Information Systems degree in Shanghai while 38\% were enrolled in a range of programs in Hobart, that are listed in Appendix 1. All graduate programs were delivered on-shore, although for the first time in 2006, it was anticipated that students from the first cohort to graduate with a UTas undergraduate degree from Shanghai may undertake an IS coursework masters degree based at Hobart. 
In recent years the teaching had become more centralised into the Hobart campus. It was not surprising, given the restricted number of programs offered beyond Hobart, that only a minority of the units available were delivered outside the Hobart campus. A limited number of units were offered at Launceston, and less were available at the Cradle Coast Campus. Increased use has been made of videoconference and other electronic means for delivery into Launceston and the Cradle Coast Campus. However, the teaching focus within an individual unit did not vary by campus. No honours or masters programs were offered in centres outside Hobart, although they had been offered in Launceston in past years.

Since the School of Information Systems had first been established, emphasis had been placed on consistent teaching across the campuses, and moderation of assessment across the multiple campuses in Tasmania. This aim was achieved by using a single point of course development for each unit, while employing teaching teams that operated across all campuses. Moreover, either single points of assessment were utilised for each unit, or team marking was used that spanned the centres. Although some divergence in delivery modes and assessment had occurred in Shanghai and Fuzhou since the IS programs were introduced there in 2003, very similar content had been retained in all units across all centres.

\section{RESEARCH ISSUES}

The research program has not been centrally controlled within the School, resulting in some variation in the nature of the research conducted within Tasmania. For example, there were few common topics between researchers in recent years other than an interest in e-commerce. The latter interest was seen by one participant to be related to the era rather than a consciously adopted focus. Another participant made reference to an early emphasis on electronic commerce in the School of IS, both from a curriculum and research perspective. The same participant identified that a driver for this emphasis was the establishment of the Tasmanian Electronic Commerce Centre, originally located within the School of IS in Hobart. A comment was made of a perceived need to focus on fewer research areas.

A decision to emphasise qualitative research methods taken in the past was still apparent in 2005, with most honours and $\mathrm{PhD}$ projects using qualitative techniques. However, in the same year, no research was undertaken by the School in the centres outside Tasmania. One participant commented that UTas did not have a distinct research identity, while several references were made to the need for a greater research culture in the School. This influence and others was seen to act against the development of research collegiality, which also hindered research. Many staff were early researchers who were still working towards completing their $\mathrm{PhD}$ or gaining expertise and recognition within their research area. Other participants referred to the lack of qualified supervisors available in the School, and the situation where one or two staff members supervised relatively large numbers of $\mathrm{PhD}$ students, in particular, Dr Paul Turner. The appointment of staff who had studied within the School led to an emphasis on one research method, which was seen as problematic by one participant.

Another local contingency to act upon research undertaken by the School of IS was the funding obtained by Senator Harradine and used in part to set up the Telstra Broadband Laboratory. The Laboratory became the focus of some of the School's research for a period. One participant referred to the proposal to amalgamate all Faculty research in a single school, while another participant pointed to the role of the Faculty of Business in identifying research areas. The appointment of the 
Woolworths Chair in IS in 2004 was described as a consequence of political pressure on the State Government to relax shop trading hours.

Other evidence was provided for the way that the nature of research conducted in the School had been influenced by local contingencies. One participant pointed to the advantages of researching in a state capital with a small population. Several references were made to the range of local industry contacts that the School drew upon, with many student projects being based within the community. The small size of Tasmania had resulted in federal and state government agencies being relatively easily accessible. In the past both tiers of government have been supportive of research that used their organisations for data collection. As a consequence, the School of IS focussed on applied projects with relevance to the industry and government bodies that participated in such research. As another example, the limited number of large private sector organisations in Tasmania had directed research efforts to the SME and public sector environments. The minimal extent of manufacturing carried out in the State has also acted to limit research undertaken through the School in this setting.

Finally, it was claimed that IT was more likely to be dealt with by accountants in the state rather than senior IT staff, while greater use of consultants and outsourcing in Tasmania were reported. All three of the latter characteristics were seen to impact on research undertaken in the School of IS.

\section{Comparison against other disciplines}

A degree of divergence was seen in the views of participants on whether IS was affected by local factors to a greater or lesser degree than for other disciplines at UTas. Several participants saw IS as being affected by local factors to a similar extent as the other disciplines within the University, while another commented that little attention was paid to all computing-related disciplines.

Two participants commented that in comparison to other disciplines at UTas, the volatility of the IS discipline meant that there was greater need to maintain the currency of the curriculum and to give students access to current technology, which had resourcing implications.

\section{IS AS A SEPARATE FIELD}

This section considers the extent to which IS has been identified as a separate field at UTas. First the degree to which IS has a separate identity will be considered, followed by a consideration of the factors that distinguish IS units and research from those found in the allied fields of Business and Computer Science. Then the status of IS academics relative to their colleagues in Business and Computer Science will be examined, before finally a comparison will be made between the terminology used by IS academics at UTas against that used by their Business and Computer Science colleagues.

\section{Extent to which IS has a separate identity}

The introduction of IS within the Department of Computer Science at UTas was an initiative of Dr Michael Rees. After his departure, Dr Chris Keen (now Professor Keen) took over the role of IS advocate. Since then IS has had a separate identity in the Faculty of Business, and communication with computing has been reduced, which, according to one participant, has been to the loss of both schools. 
Although IS at UTas was seen by the participants to have a separate identity, this characteristic had taken over ten years to achieve. Information Systems was formally acknowledged as a single field of study and research within the University since January 1997 with the formation of the School of IS. From about 1994 Information Systems was mainly associated with a group operating within the Department of Computer Science on the Hobart campus. Towards the end of that year IS was formally identified as a distinct teaching field within the Department of Computer Science. However, there was also a smaller IS teaching and research group within the Department of Applied Computing at Launceston. Referring to the time in which IS was establishing itself at UTas, a participant who had been associated with the School for many years commented that most discipline areas at the University were unclear about the nature of the field. Another participant now employed outside Tasmania saw relevance as the key for survival where confusion existed about the nature of the discipline, and both opportunities and the professional community were small.

\section{Distinguishing IS from Business and Computer Science}

In 1996 extensive discussion occurred between the staff of the proposed School of Information Systems and what were at that time the departments of Computer Science and Applied Computing. A participant reported that teaching and research topics were readily grouped into those suggested at that time by the Australian Computer Society. The topics were divided into the technical aspects of Computer Programming, Software Engineering, Networking, Computer Systems Engineering and Computer Science, and for IS, the business and social aspects of the application of ICTs. The same distinction has largely continued until 2005.

In general the participants saw computing and IS as having different perspectives, with limited recent communication between the two disciplines. However, they saw less to distinguish IS from business, with IS being concerned with the management of IT and not as broad-based as business. The IS units offered limited technical content, which is found in the School of Computing. One participant saw pressure on computing schools to shift towards information systems teaching areas, in response to falling student enrolments. As evidence of this claim, database management has been introduced by the School of Computing in some units in recent years, delivered by their own staff members. One participant saw the demise of service teaching to be partly responsible for this last development.

One participant pointed to current pressures that act against IS groups continuing as independent schools at UTas and elsewhere, suggesting that there is potential for IS to be amalgamated with other disciplines, in particular from within business, or computing.

\section{Comparative Status of IS Academics}

Four participants believed that IS academics had a similar status to Business and Computing academics at UTas. A comment was made that while IS and Business academics have the same status, academics from schools situated within the Faculty of Science and Technology have higher status, due to the better research profile in that Faculty at the University. The School of Computing is located in the Faculty of Science and Technology at UTas. However, another participant compared the size of the Schools of Computing and IS when considering the status of each. Both the Schools of Computing and IS had similar EFTSU numbers as at late 2005, with the former being the third largest school and the latter the fourth largest school in the University at that time. Finally, another participant considered IS academics to have a lower status than their colleagues in Computing or Management at UTas. 


\section{Comparative use of terminology}

Most of the participants who responded to this question considered that IS terminology used at UTas would be broadly familiar to their Business and Computing colleagues. However, one person believed that there was relatively little understanding of the conceptual base of IS among many staff in Business. Another noted the limited contact between IS and Computing staff, which, it is assumed, would make it difficult to assess the commonality in the terminology used by each group.

\section{FEATURES OF IS CURRICULUM AND TEACHING}

In the next section, the IS curriculum and teaching at UTas will be characterised. In order to do so, the place of IS service teaching will be considered, followed by an examination of whether any distinctive themes, teaching styles, tools, techniques or technologies are used for teaching IS at UTas, and other teaching issues. Finally any future plans for teaching IS at UTas are examined.

\section{Role of IS service teaching}

As the School of IS does not strongly differentiate between service and core teaching, there is less service teaching undertaken than in some other universities. For example, the same undergraduate IS units are offered within the Bachelor of Information Systems degree and its associated combined degrees, as are available across all other degrees offered by the University. A number of students undertake IS units within Business, Economics, Science, Computing, Arts and Geomatics degrees. IS degrees account for approximately $80 \%$ of the teaching load while other degrees account for approximately $20 \%$. What is commonly regarded as service teaching only occurs with the provision of two IS units within the Geomatics degree.

A pressure that acts against service teaching occurring is the motivation of other disciplines to retain funding, and, according to one participant, the limited value placed on the philosophies of other schools. There is no core IS unit in the University's MBA program, which was seen as worthy of note.

\section{Distinctive themes and teaching styles}

A focus on management and strategy was identified in the IS teaching at UTas, with less emphasis on technical issues. This focus incorporated the major themes of Project management, Data modelling, Data management and Electronic commerce. Oracle database management is taught to Oracle certification level. Oracle is taught because of its use in the Tasmanian Government, a major employer of IS graduates. At the undergraduate level there are three majors: Systems Development; E-Business and Management of IS. The approach taken in earlier years at the School when professional development was integrated into the undergraduate teaching program was seen as distinctive. However, this focus had waned more recently. The business logistics unit taught at undergraduate level was also identified as distinctive. One participant commented that the IS teaching program at UTas was not significantly different from the range of topics taught elsewhere in Australia.

Relatively few suggestions were made regarding distinctive features of IS teaching at UTas, while one participant stated that no features of the teaching program were distinctive. However, mention was made of the significant use of discussion workshops and case studies in the School. Reference was also made to the individual attention provided to students, which was perceived to foster their 
confidence and encourage them to continue on to higher degrees. Another participant commented on the high quality of the flexible online support that was provided to support the teaching program.

\section{Distinctive tools, techniques, technologies}

Although one participant commented that there were no tools, techniques or technologies that were distinctive in the IS teaching at UTas, some techniques associated with teaching delivery were identified as distinctive, including what was perceived as an effective combination of face-to-face and online delivery. Reference was made to the sequential delivery style for units from Year 1 to 3, designed to facilitate the progression of student responsibility for their own learning. For example, in the later semesters of a degree many units de-emphasised lectures to communicate knowledge, and placed more reliance on online resources with consolidation of the knowledge in workshops.

\section{Other teaching issues}

A range of teaching related issues were raised by the academics as important. Declining local enrolments was one, and the associated very high international load was another. One participant linked declining enrolments to a perceived falling interest of young people in IT, and a negative image for the discipline. Reference was also made to the associated unbalanced distribution of the teaching program across six centres, particularly as the majority of the School's students were located in China as at late 2005.

Several participants commented on the need to monitor that the programs delivered by the School of IS remained relevant to current needs and trends. In particular, several participants remarked on the need to ensure that the School's IS graduates have access to technical skills expected from employers. It was noted that in past years the School's staff had included people with expertise in advanced databases and networking, but more management oriented staff had been appointed since that time. Very recently an attempt has been made to correct this perceived imbalance through recruitment of staff with specialist technical skills. One participant no longer working in the discipline suggested the School should consider a greater degree of re-integration with computer science.

\section{Changes planned for teaching/curriculum in the next 3 years}

Finally, few changes to the nature of the IS teaching or the curriculum over the coming three years were identified. However, the new masters programs being introduced from 2006 were raised: MEBusiness, ME-Business with a Specialisation and M-Logistics.

Another participant foreshadowed a move for the School in future years away from IT and systems development, to operations management and a business process focus that will require greater coverage of business analysis methodologies. This change was regarded as a necessary response to falling enrolments. 


\section{FEATURES OF IS RESEARCH}

The features of IS research at UTas are discussed below. This section considers research output and funding, the balance between, and incentives for, research and teaching, conference attendance and planned future changes for research conducted at the School of IS.

\section{Research output and funding}

Although there was general recognition that the research output of School staff was relatively low, several participants identified that the contribution was skewed. The majority of publications were in refereed conferences, both national and international, with a limited number of quality journal publications. One participant no longer working at UTas saw an opportunity for researchers to target high quality conferences and journals, in order to obtain quality feedback. For this to happen it was identified that broadly accepted academic leadership and a unifying research culture would be required, enabling the development of research groups and the emergence of research strengths for the School.

One participant believed that in the late 1990s the School's research focussed on rigorous interpretive research methodologies. At that time it produced a series of quality $\mathrm{PhD}$ theses, evidenced by comments from staff from other schools in Australia, and the later success of some of those PhD graduates.

The School did not have a strong history of attracting ARC Discovery funding. The majority of the research funding obtained by the School of Information Systems in recent years has come from external, national competitive grants from the Smart Internet and Sustainable Tourism CRCs, and ARC Linkage grants. A limited number of the School's staff had been involved in attracting these research funds. More recently one staff member in particular had attracted considerable industry funding to the School, particularly in the area of e-health.

Small internal research grants have been made available by the Faculty of Business, while the University-wide Institutional Research Grants Scheme is designed to prepare staff for the future submission of ARC grants.

\section{Balance between research and teaching and incentives for each}

As teaching loads were high, participants perceived that pressure existed to push the balance away from research towards teaching. Some staff had a teaching and administrative load only, while several staff members had a $75-85 \%$ research load. However the majority of staff was expected to undertake teaching, research and administration.

Some participants perceived greater recognition was given for good teaching than for research at the University through processes such as teaching merit certificates, teaching development grants and evaluation of teaching and learning. However, at a Faculty level there has been a recent attempt to redress this through the introduction of research awards. Faculty funding is available to assist staff to travel to conferences, which needs to be combined with School professional development funding. A Faculty scheme of seed funding to encourage a range of different forms of research was introduced several years ago. A comment was made that incentives for the conduct of quality research could be better defined and implemented. For example, the same participant perceived that highly productive research staff did not receive recognition, or incentives through the distribution of 
research quantum income. The same participant considered that the DEST point system to be ineffective in challenging staff to undertake better research. However, the new approach of the Commonwealth Government to research outcomes in Australian universities may redress this situation.

Research and teaching targets for individual staff are set within the compulsory Performance Management scheme implemented at UTas. Promotion is linked to good research outcomes, and more recently, an alternative route to promotion has been introduced through the demonstration of quality teaching.

\section{Conference attendance}

It was believed that active researchers in the School would attend on average one to two conferences a year. In the past the Australasian Conference of IS (ACIS) has been popular with staff and research students because it provides researchers with opportunities to network. However, one participant commented that attendance at ACIS by school staff had declined in recent years. ICIS, ECIS, HICSS, GITMA, IRMA and other topic specific national or regional conferences have been attended occasionally by at least one staff member, while healthcare and security conferences have been popular.

\section{Changes planned for IS research over the next 3 years}

Finally, few comments were made on changes planned for research in the School of IS in coming years. Associated with the relatively recent appointment of a Woolworths Chair in IS at the School, several participants referred to a new focus on IT governance and business process management. This move was seen as having potential to benefit the School, and several comments related to a desire for the emergence of a collegial research culture. However, while a senior participant foreshadowed a limited research group culture for the future, based on the belief that it is not possible to "bureaucratise IS research", another saw progress of the IS discipline at UTas as being linked to the future research performance of the School.

\section{KEY PEOPLE WHO HAVE IMPACTED IS}

The last section in the analysis and findings for Level One considers key people who have impacted IS at UTas.

While a range of individuals was identified as having impacted IS at UTas, only two were mentioned by more than one participant. Professor Chris Keen was the individual mentioned most frequently. He was seen to be responsible for the inception of the School of Information Systems, and acknowledgement was made of his considerable entrepreneurial skills and vision. Reference was also made to his influence on some of the current staff members as their supervisor while they completed their PhD. The role of Professor Arthur Sale was also acknowledged for recognising the need to introduce a more applied course in ICT at UTas when he was Head of the Department of Computer Science.

Other individuals were mentioned once by participants. Jeremy Firth and Stephen Haynes from the Tasmanian public sector were described as strong advocates for an IS program at UTas in the 1990s. Reference was also made to the contribution made by Cathy Urquhart and her role in the 
development of the first IS course at UTas, and John Lamp, for his development of a web-based service for the Australasian and international IS community. Bob Godfrey's role within the Australian Computer Society and his involvement with the development of IS curricula was also acknowledged. More recent contributions that were recognised included Paul Turner's strong engagement with industry, Peters Marshall's focus on research and Roy Barkas's role within Logica CMG in hiring IS graduates and providing assistance with research.

Section 4 has presented the findings for Level One, providing a descriptive examination of IS at UTas, drawing upon qualitative and quantitative sources. This section first considered the demographic characteristics of the respondents, the administrative placement of the School of IS and the size of the IS presence at UTas. Then the findings and discussion were presented for the five themes common to the reports from each region in Australia.

The following section sets out the analysis and findings for Level Two of this study, and examines whether an inverse relationship could be identified between the impact of local contingencies on the IS discipline, and the degree of professionalism, within the UTas setting.

\section{ANALYSIS AND FINDINGS: LEVEL TWO}

Figure 1B of the theoretical framework guiding the study postulated an inverse relationship between the impact of local contingencies on the IS discipline, and its degree of professionalism. The reader is referred to the earlier chapter in this volume on the study's theoretical framework for an extended explanation of these two terms, and the relationship between them.

The impact of local contingencies at the School of IS at UTas was evaluated by categorising the Level One data relating to both research and teaching issues, including the variation in both by centre, into high, medium or low impact. Non-local factors were omitted. Where the categorisation by the second researcher differed, discussion took place until agreement was reached. Both qualitative and quantitative data were considered, where relevant. This analysis is presented below.

\begin{tabular}{|c|c|c|c|}
\hline Area & High & Medium & Low \\
\hline $\begin{array}{l}\text { IS curriculum \& teaching } \\
\text { issues }\end{array}$ & $\begin{array}{l}\text { 3-campus delivery of IS in } \\
\text { Tasmania influenced } \\
\text { by politicians } \\
\text { Oracle taught because of } \\
\text { its use in the } \\
\text { Tasmanian } \\
\text { Government, the } \\
\text { major employer of IS } \\
\text { graduates }\end{array}$ & $\begin{array}{l}\text { Funding pressures make } \\
\text { adjusting staff profile } \\
\text { to student demand } \\
\text { difficult } \\
\text { Role of course advisory } \\
\text { committees, } \\
\text { particularly for MIS } \\
\text { degree } \\
\text { Increased use of } \\
\text { videoconf, WebCT for } \\
\text { teaching non- Hobart } \\
\text { campuses } \\
\text { Some variation in delivery } \\
\text { to Shanghai \& Fuzhou }\end{array}$ & $\begin{array}{l}\text { Teaching focus does not } \\
\text { vary by campus } \\
\text { Moderation undertaken } \\
\text { across multiple campuses } \\
\text { Team marking across } \\
\text { campuses } \\
\text { Single points of course } \\
\text { development for each } \\
\text { unit } \\
\text { Very similar unit content } \\
\text { across all centres } \\
\text { Teaching fairly centralised } \\
\text { in Hobart }\end{array}$ \\
\hline
\end{tabular}




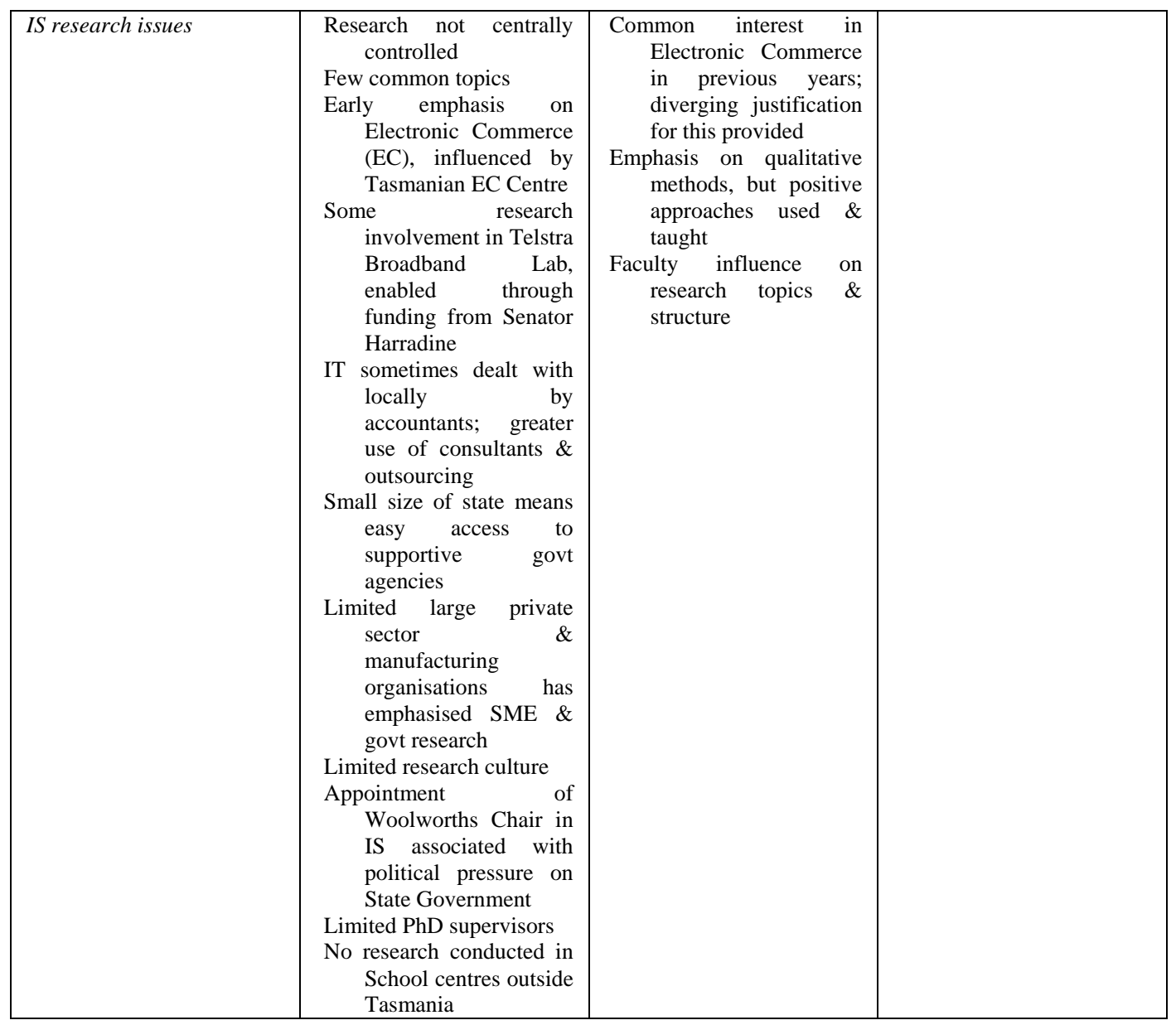

Table 4 Classification of impact of local contingencies on research and curriculum/teaching

Overall, it can be seen from Table 4 that local contingencies had a low to medium impact on curriculum and teaching issues, while they had a high to medium impact on research issues. Research was particularly influenced by local factors, with no issues recorded in the low range, and few in the medium range. Next, an analysis of the extent of professionalism of the IS discipline at UTas follows.

The degree of professionalism for both research and teaching issues at the School of IS at Hobart was also evaluated using the Level One data, employing the same method used for the evaluation of the impact of local contingencies. Professionalism requires high task certainty, routinisation of activities and a clear division of labour.

Table 5, below, suggests that IS curriculum and teaching activities had a high to medium level of professionalism at UTas, while research activities had a low to medium degree of professionalism. 


\begin{tabular}{|c|c|c|c|}
\hline Area & High & Medium & Low \\
\hline $\begin{array}{l}\text { IS curriculum \& } \\
\text { teaching issues }\end{array}$ & $\begin{array}{l}\text { Relatively centralised } \\
\text { location of staff in Hbt } \\
\text { aids task certainty } \\
\text { through opportunities } \\
\text { for communication } \\
\text { Moderation of teaching } \\
\text { across campuses } \\
\text { Similar teaching content } \\
\text { across campuses } \\
\text { High quality flexible online } \\
\text { support is an example of } \\
\text { clear division of labour } \\
\text { in this area } \\
\text { Widespread use of } \\
\text { workshops and case } \\
\text { studies in teaching } \\
\text { Range of mechanisms exist } \\
\text { to promote good } \\
\text { teaching } \\
\text { Sequential delivery style } \\
\text { used to develop student } \\
\text { responsibility from } \\
\text { Years } 1 \text { to } 3 \\
\text { Focus on management \& } \\
\text { strategy in teaching } \\
\text { Four major teaching themes } \\
\text { identified }\end{array}$ & $\begin{array}{l}\text { Staff performance } \\
\text { management scheme } \\
\text { sets teaching targets } \\
\text { Little emphasis on service } \\
\text { teaching means } \\
\text { greater routinisation } \\
\text { across degrees } \\
\text { Oracle certification is an } \\
\text { example of high task } \\
\text { certainty }\end{array}$ & \\
\hline IS research issues & & $\begin{array}{l}\text { Some emphasis on } \\
\text { qualitative research } \\
\text { methods } \\
\text { Perceived fewer } \\
\text { incentives for } \\
\text { research than for } \\
\text { teaching } \\
\text { Some incentives provided } \\
\text { by Faculty/University } \\
\text { to do research } \\
\text { Some emphasis on SME } \\
\text { \& govt research } \\
\text { New focus on IT } \\
\text { governance, business } \\
\text { process management } \\
\text { Majority of staff expected } \\
\text { to undertake research }\end{array}$ & $\begin{array}{l}\text { Research program not } \\
\text { centrally controlled } \\
\text { Few common topics } \\
\text { Research culture hard to } \\
\text { sustain, detracting } \\
\text { from routinisation of } \\
\text { research lack of } \\
\text { Perceived lod } \\
\text { recognition ron for } \\
\text { productive research } \\
\text { staff } \\
\text { Limited history in } \\
\text { attracting ARC funds } \\
\text { Less attendance at } \\
\text { conferences than in } \\
\text { past need to focus } \\
\text { Perceived need research } \\
\text { on fewer } \\
\text { areas } \\
\text { Limited quality journal } \\
\text { publications reduces } \\
\text { task certainty for } \\
\text { publishing in these } \\
\text { journals } \\
\text { High teaching loads } \\
\text { leaves little time to } \\
\text { routinise research }\end{array}$ \\
\hline
\end{tabular}

Table 5 Classification of features of IS research and curriculum and teaching at UTas by degree of professionalism 
Now that the Level Two analysis has been undertaken, the conclusions of this study will be considered next.

\section{CONCLUSIONS}

This final section reviews the findings, and presents the study's limitations and suggestions for future research.

In the descriptive analysis of the School of IS at the University of Tasmania, the extent to which IS was impacted by local factors, whether it was perceived to be a separate field at the University, the distinctive characteristics of both its curriculum and research and the key people who had impacted IS at UTas were considered. Then an analysis was undertaken of the perceived degree of impact of local contingencies and the degree of professionalism for both teaching and research for IS at UTas.

The Level Two analysis suggests that while local contingencies had a low to medium impact on curriculum and teaching, at the same time they also had a high to medium impact on research issues. However, there were indications that the reverse was the case for the degree of professionalism, in that curriculum and teaching issues had a high level of professionalism while research activities were assessed as low to medium. These findings for research issues are consistent with the view of IS as a fragmented adhocracy, as explained in the framework paper earlier in this volume. However, the different findings for curriculum and teaching issues have not, it is believed, been identified before for IS, and make a contribution to research on the development of this discipline.

The Level Two findings are consistent with the postulation from the theoretical framework that an inverse relationship exists between the impact of local contingencies on a discipline and its degree of professionalism. However, as the findings were derived from a single case study, the inverse relationship found is best confirmed by case studies conducted in other areas of Australia and elsewhere. Moreover, if the findings are confirmed in different regions using different methods of analysis, this characteristic will act to strengthen the findings.

Additional future work planned is to examine the remainder of the theoretical framework developed for the study through a cross-case analysis of how the components of the IS discipline developed over time. It is possible that the framework may need modification as a result of its application to further cases. Once these Level Three findings are known, comparison can be made with the European and North American studies to see if the common findings of those two studies extend to Australia at least six years later. 


\section{REFERENCES}

Avgerou, C., Siemer J., \& Bjorn-Andersen, N. (1999) “The Academic Field of IS in Europe”, European Journal of Information Systems, Vol 8 No 2, pp 136-153.

Dixon-Woods, M., Agarwal, S., Jones, D., Young, B., \& Sutton, A. (2005) "Synthesising Qualitative and Quantitative Evidence: A review of possible methods", Journal of Health Services Research \& Policy, Vol 10 No 1, pp 45-53.

IRMA (1996) The Information Resources Management Curriculum Model: An international curriculum model for a 4 year undergraduate program in IRM. A joint activity of IRMA and DAMA, IRMA, Harrisburg, PA.

Longnecker, H., Clark, J., Couger, D. Feinstein, D. \& Clark, J. (1995) IS’95: Model curriculum and guidelines for undergraduate degree programs in information. A joint activity of DPMA, ACM, ICIS and AIS, School of CIS, University of South Alabama, Mobile, AL.

Ridley, G., Goulding, P., Pervan, G., \& Lowry, G. (1998) “The Australian Information Systems Research Community: An analysis of mainstream publication outlets”, Australian Journal of Information Systems, Vol 5 No 2, pp. 69-80.

Ridley, G. (1996) "Establishing Australian IS Research Traditions: Identifying appropriate quality publication outlets and the significance of conference publications", Proceedings of the 7th Australasian Conference on Information Systems, Hobart, Vol 2, pp 567-578.

Ridley, G. (2006) “Characterising Information Systems in Australia: A Theoretical Framework”, Australasian Journal of Information Systems, Vol 13 No 3, pp. 38-60.

University of Tasmania (1996) Welcome by the Vice-Chancellor, Available: http://www.utas.edu.au/uni/welcome.html accessed 22 November 2005.

Yin, R. (2003) Applications of Case Study Research ( $2^{\text {nd }}$ Edn), Sage Publications, Newbury Park, CA.

Walsham, G. (1995) “Interpretive Case Studies in IS Research: Nature and Method”, European Journal of Information Systems, Vol 4 No 2, pp 74-81.

Watson, H., Taylor, K., Higgens, G., Kadec, C. \& Meeks, M. (1999) "Leaders Assess the Current State of the Academic IS Discipline”, Communications of the AIS, Vol 2.

Whitley, R. (1984) The Intellectual and Social Organization of the Sciences, Clarendon Press, Oxford, UK.

\section{THE AUTHOR}

Dr Gail Ridley is employed as a lecturer in the School of Accounting and Corporate Governance within the Faculty of Business at the University of Tasmania in Australia. She is based at the Hobart campus. Her teaching interests include Strategic Information Systems, Information Systems Research Methods, Systems Development Methodologies and Accounting Information Systems. Her research interests include Information Systems research methods, IT governance and IT control frameworks. Gail has published in both international and Australian journals and conferences, and has worked as a consultant to government in the strategic information systems domain. 


\section{APPENDIX 1}

Programs offered at the School of Information Systems, University of Tasmania, as at Semester 2, 2005

\begin{tabular}{|l|}
\hline Undergraduate \\
\hline BIS * \\
\hline BIS/BBus \\
\hline BIS(Hons) \\
\hline BIS/BMusic \\
\hline BIS/BTeaching \\
\hline BIS/BLaws \\
\hline BFA/BIS \\
\hline BIS/DipIT*** \\
\hline PG coursework \\
\hline MIS \\
\hline GDIS \\
\hline GDInfoMgt $* *$ \\
\hline GCIS \\
\hline RHD \\
\hline PhD \\
\hline
\end{tabular}

* in 3 specialisations: Management of Information Systems, Electronic Business, Systems Development

** in 3 specialisations: General Librarianship, Teaching-Librarianship, Information Management *** the DipIT component is delivered by TAFE 